\title{
Mostra de Imagem e Questão Social
}

\author{
Elziane Dourado (Ziza D.)*
}

As imagens, além de objetos, são formas de ver e pensar a realidade (SAMAIN, 1998, p.11) e, portanto, constituem uma área de conhecimento em que há diferentes questões teórico-metodológicas implicadas em sua forma e conteúdo. Com características próprias constroem, a seu próprio modo, um campo particular de conhecimento. Podem ser singularizadas pela conformação de sua forma de construção, veiculação e recepção, sempre marcadas pelas contínuas renovações técnicas e pelo experimentalismo de linguagens dentro de uma dada concepção histórica, social, política, cultural e econômica de sociedade. Nos interessa aqui imagens que apresentam relações com áreas fronteiriças como a arte e a política.

A Mostra "Imagem e Questão Social" é fruto do trabalho de assistentes sociais, educadores, artistas visuais, militantes de movimentos sociais, estudantes, professores e pesquisadores vinculados ao Laboratório de Imagem da Faculdade de Serviço Social da UERJ (Li/UERJ)' ${ }^{1}$. Resultantes de trabalhos artísticos autorais e/ou coletivos, em parcerias transversais ao espaço institucional do Laboratório de Imagem (Li), desde a fase preliminar à sua institucionalização, as imagens selecionadas e aqui apresentadas utilizam o suporte fotográfico como referência e ponto de partida, sendo que algumas delas sofrem interferências plásticas das mais diferentes ordens e matérias, revelando as potencialidades da imagem fixa e suas singularidades, seja como representação da realidade em uma perspectiva mais realista, seja na sua natureza declaradamente ficcional e poética.

As imagens aqui expostas são muito mais que sucessões de acontecimentos e narrativas lineares que oferecem conforto ao público carente de um olhar seguro, conhecido e, de certa forma, familiar. São processos históricos que revelam o espaço e tempo de recusa de uma série de con-

\footnotetext{
* Assistente social, professora e Coordenadora do Laboratório de Imagem da Faculdade de Serviço Social da Uerj, artista visual, diretora Cultural da Chave Mestra - Associação dos Artistas Visuais de Santa Teresa, desenvolve pesquisas na área de "Imagem e "questão social".

1 O Laboratório de Imagem (Li) é um espaço interdisciplinar e interprofissional de experimentação imagética. Através de uma dinâmica horizontal, com as instituições e movimentos sociais parceiros, pretende-se implementar uma metodologia de intervenção social que articule os recursos imagéticos expressivos, formais e temáticos da imagem em torno do conhecimento crítico sobre a realidade brasileira. Formalizado como projeto de extensão em 2015, reúne artistas visuais, estudantes, professores e pesquisadores das ciências humanas e sociais, assistentes sociais, militantes e movimentos sociais em torno do estudo/produção/pesquisa da imagem em suas mais diferentes expressões e formatos. Privilegiando o estudo imagético da "questão social", procura desmistificar o conhecimento dos processos de produção, realização, exibição e circulação de imagens na sociedade contemporânea, enfatizando o uso das novas mídias digitais como forma de acesso mais democrático ao conhecimento e criação das imagens.
} 


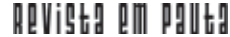

\} MOSTRA DE IMAGEM E QUESTÃO SOCIAL - DORADO, E. \}

DOI: 10.12957/rep.2015.21074

venções porque constroem seu sentido social e político no ato de resistência a homogeneidade no constructo da percepção visual tanto em sua produção, quanto em sua circulação e exibição. Tem sua força na heterogeneidade de imagens que traduz a sensibilidade de cada autor em seu processo de criação, marcado pela forma pela qual se relacionam com o mundo e com suas próprias subjetividades.

Essa mostra é um convite à percepção e experiência do leitor/ observador por isso apresenta bifurcações, possibilidades de reinvenções, múltiplos sentidos e narrativas que revelam sujeitos políticos que, em sua grande maioria, não estão inseridos e reconhecidos como "profissionais" das imagens, embora utilizem do olho-câmera para instigar a não conformação e domesticação do olhar. Têm em comum, além da participação no Laboratório de Imagem (Li), a disposição para se expor e para partilhar, com suas imagens, o caráter rico de significado de seus trabalhos.

Por isso, embora importante, os trabalhos apresentados não recaem sobre a técnica como a força motriz na seleção dos trabalhos, pois o que se privilegiou foi o depoimento, através das imagens que aqui se constituem realidades, experiências e não mercadorias disponíveis ao prazer. Se assim o fosse, essa mostra se tornaria completamente dispensável, considerando a oportunidade inovadora criada pela revista Em Pauta, ao constituir um espaço para muito além do devaneio contemplativo - o reconhecimento de que a imagem é uma linguagem, uma experiência, uma expressão direta de um modo de ver, viver e pensar a realidade, isto é, um campo aberto a experimentações e pesquisas.

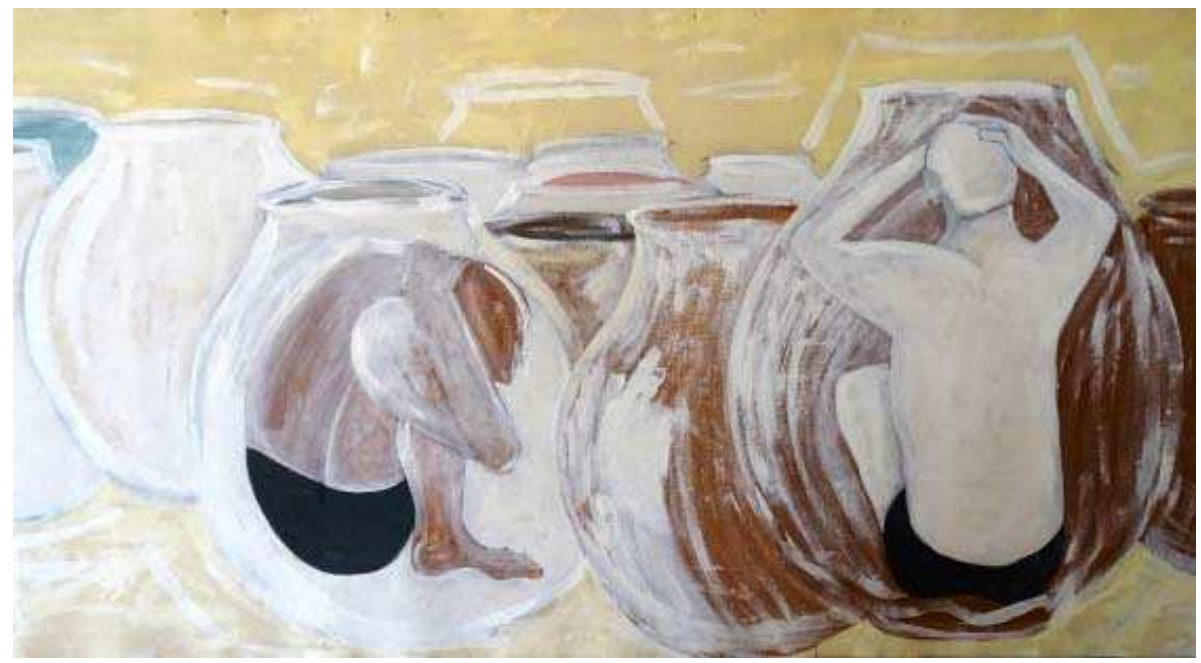

Figura 1 (Foto de tela de Regina Marconi) 


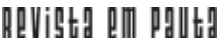

\} MOSTRA DE IMAGEM E QUESTÃO SOCIAL - DORADO, E. \}

DOI: $10.12957 /$ rep.2015.21074

Regina Marconi parte de imagens de mídia impressa que lhe evocam outras imagens e, indo além dessa sua primeira impressão, interfere com inúmeras camadas de tinta e lembranças encobrindo, reinventando e integrando em diferentes suportes e temporalidades distintas a memória social de sujeitos coletivos. Tal qual os materiais utilizados, tradicionais e experimentais, que convivem e se completam, as imagens são buscadas em diferentes personagens e épocas.

A imagem contemporânea, veiculada pela imprensa, convive com imagens remotas dotando de realismo poético a relação arte e política. Essa perspectiva passeia por materiais distintos, onde o tempo pode se perpetuar na previsão da durabilidade da tela de pintura (figura 01) e/ou na efemeridade da foto-aquarela sob o papelão (figura 02). Em ambos trabalhos coexistem temporalidades e espacialidades distintas.

Os presos despidos e encolhidos, num canto da imagem do jornal, evocam vasos de barro que encerram, na sua própria materialidade, a necessária contenção para garantir a pretensa segurança de uma sociedade que utiliza, além de sua força bruta, aspectos simbólicos na construção de suas narrativas visuais.

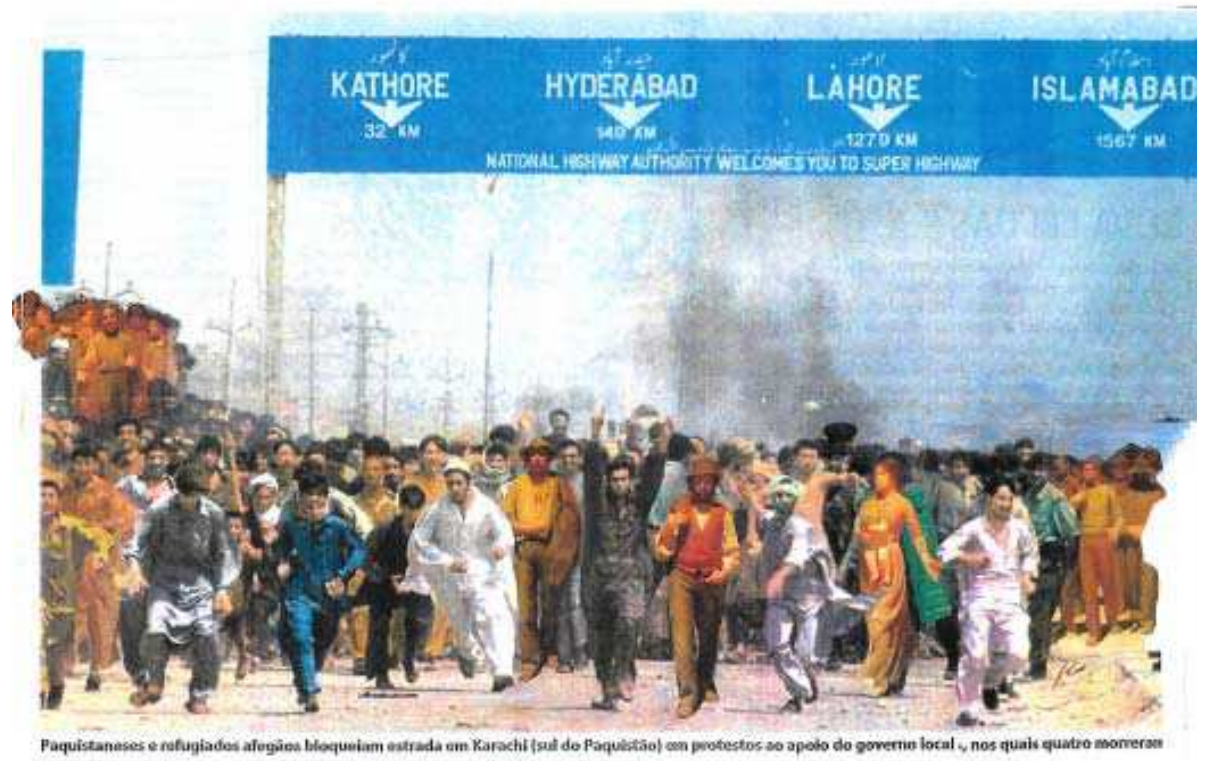

Figura 2 (Foto-aquarela de Regina Marconi)

Os presos contidos se contrapõem ao movimento das massas, do coletivo, de quem se apercebe como parte de uma força política - um sujeito social que luta para transformar a realidade que lhe é imposta. Assim, 


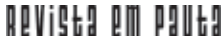

\} MOSTRA DE IMAGEM E QUESTÃO SOCIAL - DORADO, E. \}

DOI: 10.12957/rep.2015.21074

em "A coisa imaginada"2 há coexistência de imagens perpetuadas na obra de arte II Quarto Stato (1901), de Pelizza da Volpeto (figura 2), entrelaçadas com aquelas recolhidas das primeiras páginas de jornais de protestos em Cabul e Paquistão: "Nesse movimento, onde o antigo e o contemporâneo coexistem, a poética revê a história através de registros perpetuados pela arte ou pelo descartável e simples jornal cotidiano" (MARCONI,2014). A artista reconhece as diferentes dimensões de exploração da imagem fotográfica para além de sua representação realista, esgarçando as suas áreas fronteiriças com as artes plásticas.

Elziane Dourado (Ziza D) expõe o trabalho intitulado "Brado visceral" (figura 3) que é fruto de uma relação de cooperação do Laboratório de Imagem (Li), da Faculdade de Serviço Social/UERJ, com a Federação de Órgãos para Assistência Social e Educacional (Fase-Rio) em torno de projeto "Desenvolvimento urbano e violência institucional: os impactos da militarização da cidade na vida das mulheres", em parceria com mulheres moradoras de Manguinhos, São Carlos e Caju, e com o apoio da Fundação Böll, da Justiça Global, do Laboratório de Imagem (Li)/Faculdade de Serviço Social da UERJ, do Núcleo de Pesquisas Associações, Solidariedade e Política (Nupesp) da UFRJ, no período de 2014 e 2015.

O ato público realizado pelas mulheres do projeto, em meados de dezembro último, no centro da cidade do Rio de Janeiro, mais precisamente no Largo da Carioca, foi um dos marcos deste projeto. Ali as mulheres declararam seu brado - em um ato de resistência política, social e psíquica - e denunciaram as suas experiências pessoais frente às ações de barbárie da violência institucional praticada pelo Estado nos territórios nos quais vivem e/ou trabalham. Dando voz a cada violência sofrida, as mulheres reagiram com bravura e coragem às suas próprias dores.

O bumbo estabelecia o ritmo das narrativas, em um grande círculo no qual elas se juntaram e, muito além do tempo presente, o som marcava as vozes, as lágrimas, o lamento e o grito de guerra chamado por nós de "brado visceral", que marcava e demarcava cada uma das narrativas: mães que tiveram os filhos bárbara e covardemente assassinados, presos e esculachados pelos "homens de farda". Mulheres, vítimas de violência das mais diferentes espécies. Todas essas experiências reverberavam ali e silenciavam os passantes no correcorre da cidade grande, registradas por diferentes meios visuais e sonoros câmeras e microfones foram utilizados por várias organizações sociais e militantes como instrumentos de amplificação das questões ali colocadas.

Como registrar imageticamente esse complexo processo de luta, resistência e companheirismo forjado entre essas mulheres? Como traduzir essa força extraída de grandes dores? Como sintetizar essa reação visceral pela própria vida e daqueles que lhe são queridos?

${ }^{2}$ Série de trabalhos da artista que utilizam imagens veiculadas pela mídia entrelaçadas com imagens de arte. 


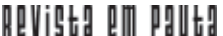

\} MOSTRA DE IMAGEM E QUESTÃO SOCIAL - DORADO, E. \}

DOI: 10.12957/rep.2015.21074

"Brado visceral" traduz, assim, a partir da repetição de imagensacontecimentos, gestos significativos de construção - pela corporalidade da resistência e luta das mulheres contra a violência em suas múltiplas dimensões. Os gestos das mãos, captados em momentos diversos das oficinas com as mulheres, espelham a força do trabalho coletivo, organizado e combativo que resultou no ato público por nós brevemente descrito. A composição das micronarrativas trata de imagens fotográficas com interferências digitais. Quando olhamos uma imagem seja na sua produção, edição ou análise, sempre o fazemos a partir de determinado ponto de vista, de um recorte do real visto sob uma visão social de mundo singular.

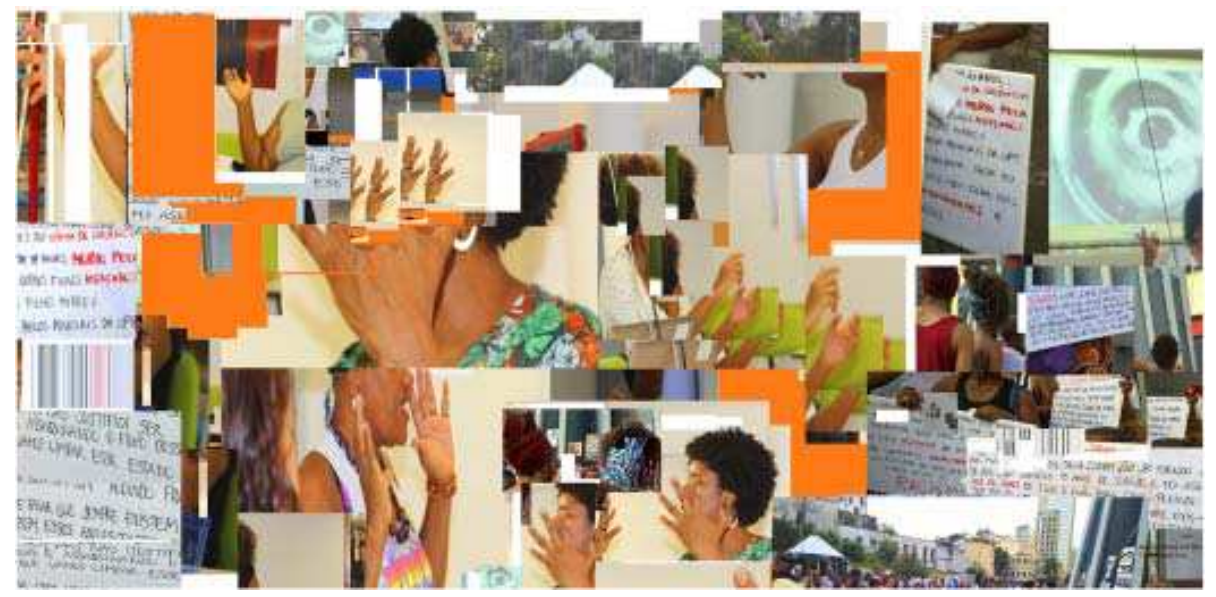

Figura 3 (Foto-montagem de Elziane Dourado)

Já a imagem do olho mecânico da câmera, retirada do filme " $O$ homem com uma câmera", do cineasta russo Dziga Vertov, realizado em 1929, insiste, em sua repetição, no necessário engajamento político crítico que pode ter a imagem, o olhar no trabalho social. Na imagem partida do lado superior direito do quadro - onde não percebemos imediatamente tratar-se de um espaço institucional acadêmico - há a demarcação que explicita o lugar que a realidade ocupa em nossas reflexões no Li, nas quais tanto "o quadro", quanto "o fora do quadro" (DOURADO, 2012) constituem o espaço-tempo rico de significações e provocam uma relação dialógica com o público. Simbólica e intencionalmente, o espaço acadêmico ocupa, nesse processo de criação, a periferia do quadro, marcando a importância dos sujeitos coletivos, embora o olhar analítico, reiterado pelo olho-câmera, denuncie o necessário desvendar daquilo que é aparência e indica, também, através da presença da imagem da autora junto a imagem câmera, a dimensão investigativa do olhar a partir das (e sobre as) imagens. 


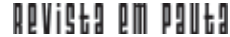

\} MOSTRA DE IMAGEM E QUESTÃO SOCIAL - DORADO, E. \}

DOI: $10.12957 /$ rep.2015.21074

$\mathrm{Na}$ análise geral da composição plástica da imagem é possível notar os intervalos e interrupções que delimitam, não fragmentando, a dinamicidade própria de espaços e tempos envolvidos na organização da resistência política. A edição de imagens é vista não como somatório de fluxos contínuos narrativos, mas como potência criadora de novos significados. Assim, o olhar e o trabalho da artista traduzem um ato-posicionamento político-ideológico em que o estético esta intrinsicamente ligado ao constructo da própria vida e do sujeito em sua historicidade. Não por acaso, o trabalho trata da memória de um trabalho social, enquanto espaço de tensão e de luta, onde a força das imagens centra-se na expressão propriamente dita da resistência, vista como a capacidade de ir além da crítica para uma estratégia de intervenção política de confronto com o status quo.

Monica M. Torres de Alencar escolheu a fotografia para explorar, de modo inteiramente diverso, a construção da paisagem urbana. (Figura 4).

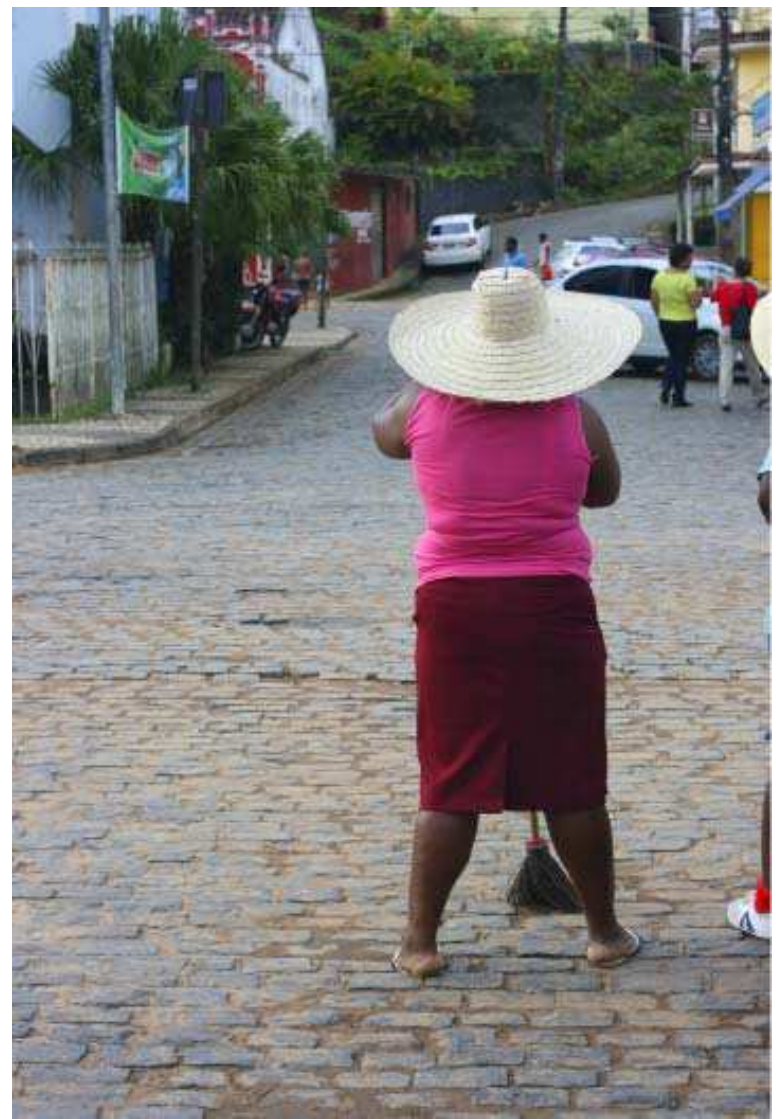

Figura 4 (Foto de Mônica M. Torres de Alencar)

EM PAUTA, Rio de Janeiro - $2^{\circ}$ Semestre de 2015 - n. 36, v. 13, p. 311 - 323 


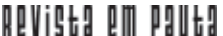

\} MOSTRA DE IMAGEM E QUESTÃO SOCIAL - DORADO, E. \}

DOI: $10.12957 /$ rep.2015.21074

Monica trata da poética do trabalho, a partir do registro da imagem de uma trabalhadora que varre a rua em uma pequena cidade da Bahia. Momento de devaneio frente a uma jornada de trabalho longa ao sol do verão nordestino. A construção do espaço do trabalho e do devaneio no decorrer da jornada de trabalho é revelada pela delicadeza do olhar da artista, que desvela outras tramas constitutivas da imagem fotográfica sobre a relação dos homens com o seu trabalho.

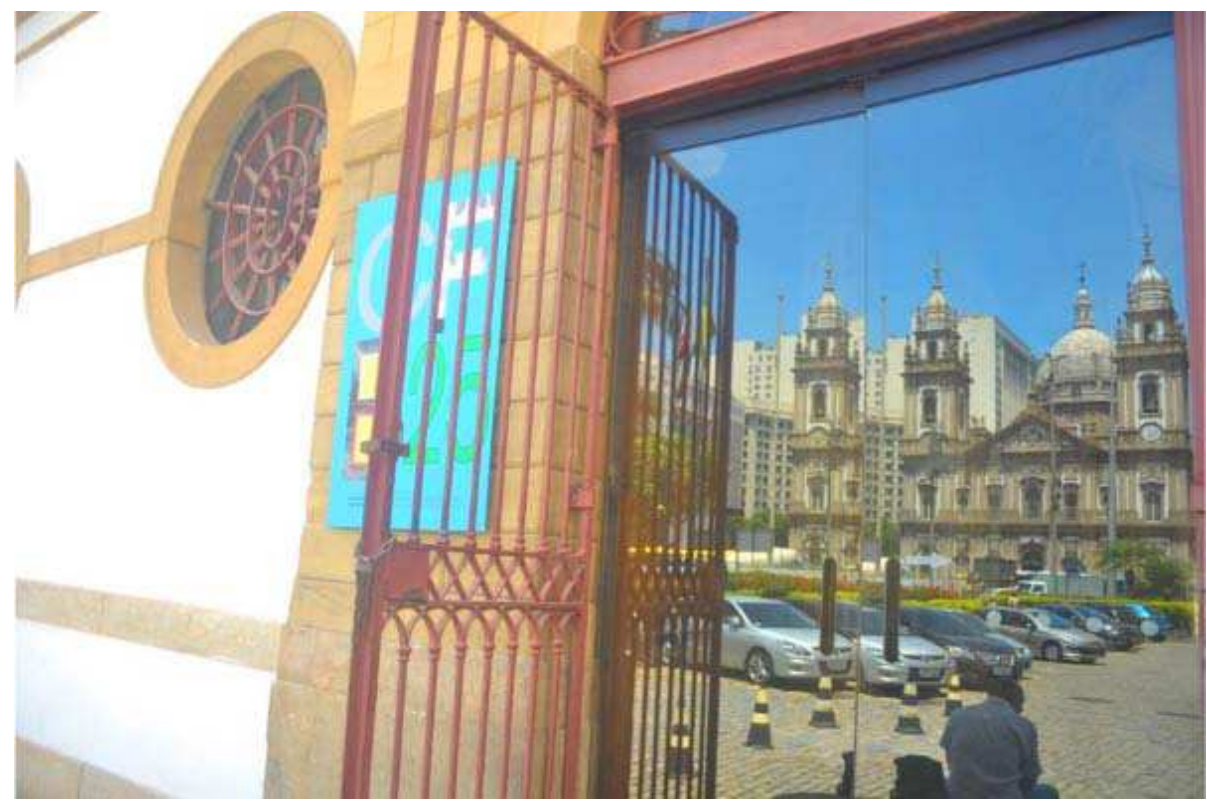

Figura 5 (Igreja da Candelária. Foto de Carolina Novaes

Carolina Novaes nos apresenta a possibilidade de mobilizar o olhar para um território no qual o burburinho da cidade se distancia a partir da abertura de um portal que emoldura o cartão postal da Igreja da Candelária. Instante de captura da imobilidade urbana (figura 5) que é reforçado pela sensação de tranquilidade e proteção do ciclista. 


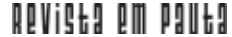

\} MOSTRA DE IMAGEM E QUESTÃO SOCIAL - DORADO, E. \}

DOI: $10.12957 /$ rep.2015.21074

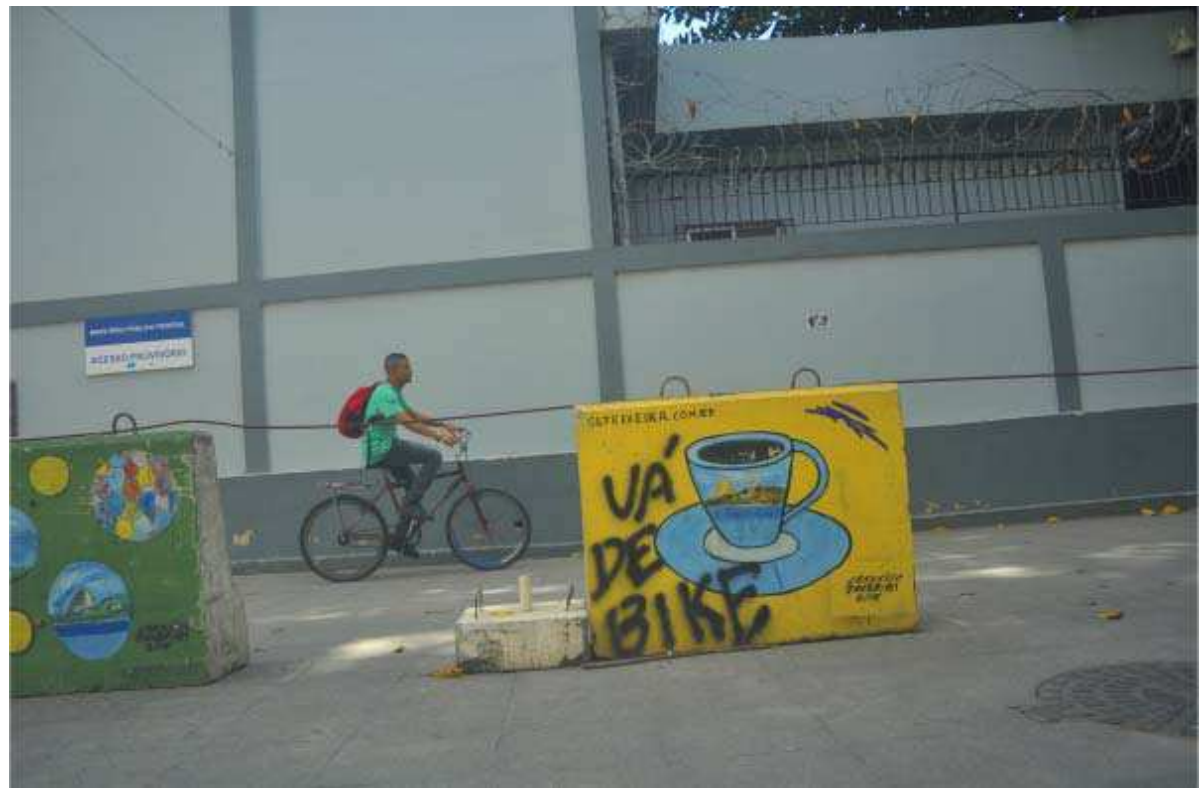

Figura 6 (Foto de Carolina Novaes)

No entanto, há um corte retilíneo nesta última imagem que conduz para um ponto de observação em movimento que só é interrompido quando observamos a cerca de arame que se encontra acima no lado direito do quadro. Percebemos então as tensões possíveis de uma vida aparentemente pacata. Realidade e ficção aqui são indícios de questões importantes para a imagem fotográfica. 


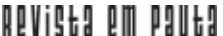

\} MOSTRA DE IMAGEM E QUESTÃO SOCIAL - DORADO, E. \}

DOI: $10.12957 /$ rep.2015.21074

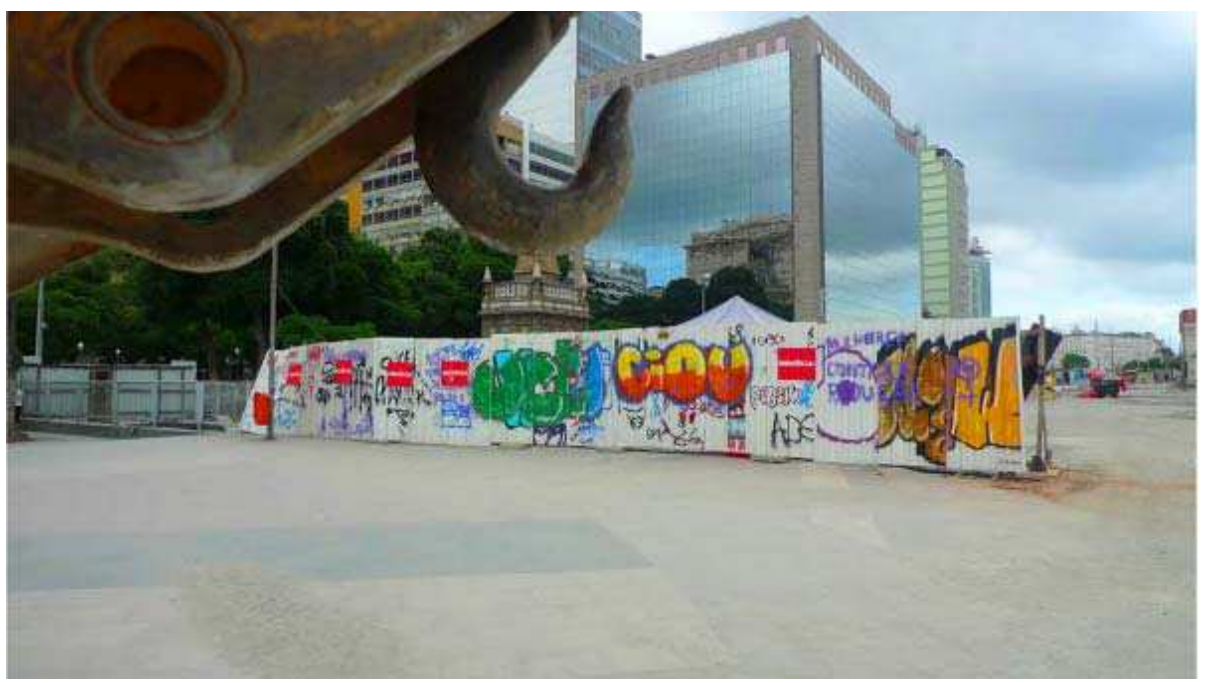

Figura 7 (Foto de Glória Coutinho)

Glória Coutinho (figura 7) e Talitha Vaz (figura 8) escolhem caminhos distintos para revelar a agressividade da cidade. Glória insiste na mudez da matéria rígida que se impõe sob as diferentes camadas da realidade que a profundidade de campo possibilita captar no espaço citadino do Rio de Janeiro e, como roteirista que é, nos propõe inúmeras possibilidades narrativas. Já Talitha enfatiza a dinamicidade social, tanto no possível diálogo dos policiais quanto no processo educativo explícito no outdoor. Capturando de forma fortuita, para não ser observada faz um corte rápido e preciso escolhendo a indagação como percurso ao traçar uma linha tensa de continuidade entre as duas imagens no quadro. 


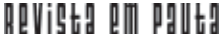

\} MOSTRA DE IMAGEM E QUESTÃO SOCIAL - DORADO, E. \}

DOI: 10.12957/rep.2015.21074

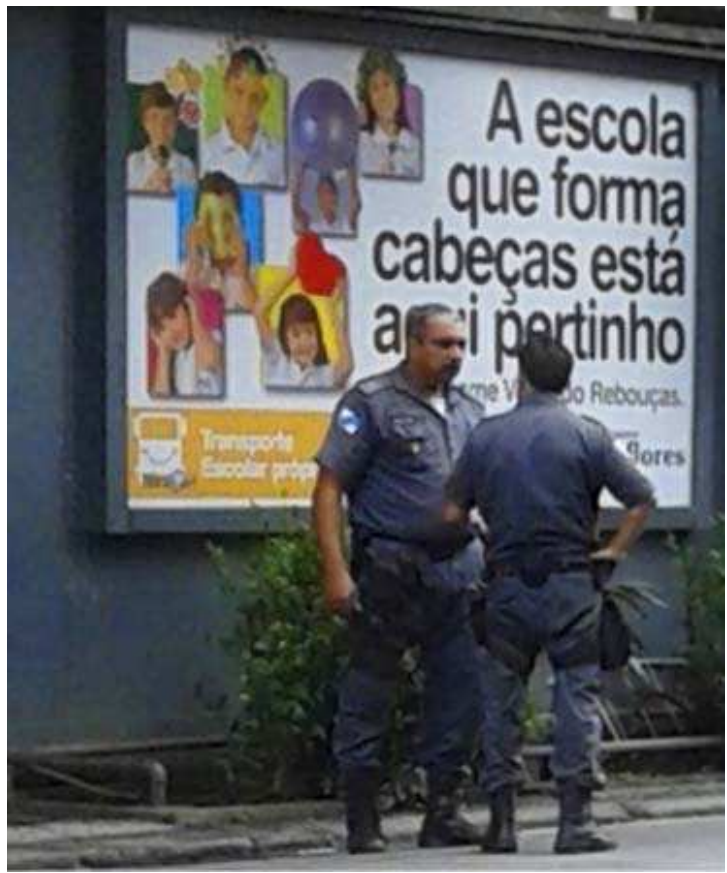

Figura 8 (Foto de Thalita Vaz)

Elizabete Pacheco Gandra (figura 10) opta pela denúncia direta da omissão do Estado quanto ao saneamento básico, escolhendo seus percursos na cidade como caminho para as suas imagens. Revela um bairro da periferia carioca em uma situação de enchente e, portanto, a convivência diária com a falta de políticas públicas, que envolve desde as limitações na mobilidade urbana ao risco do ir e vir cotidiano, até resvalar para aquelas mais graves relacionadas ao processo saúde-doença dos que ali moram e/ ou trabalham. 


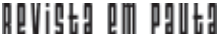

\} MOSTRA DE IMAGEM E QUESTÃO SOCIAL - DORADO, E. \}

DOI: 10.12957/rep.2015.21074

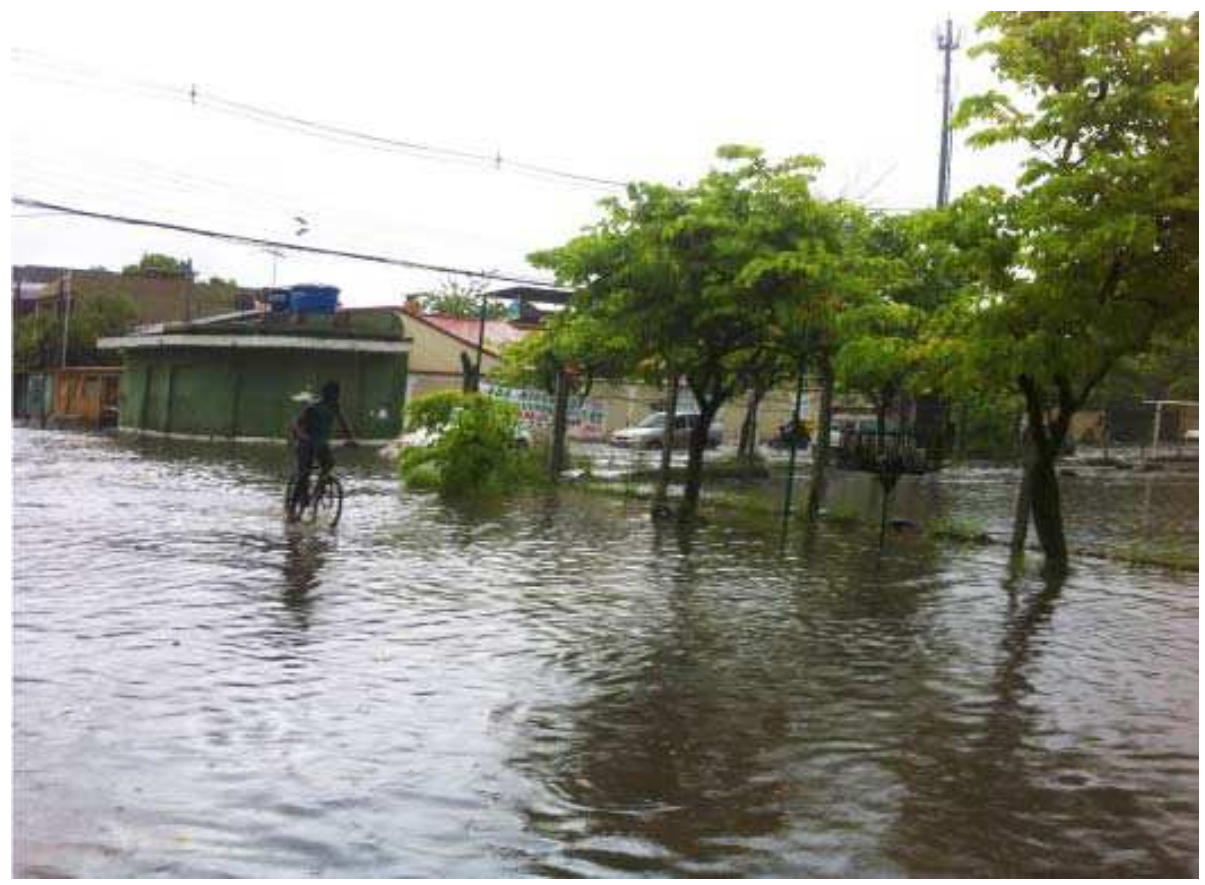

Figura 9 (Foto de Elizabete Pacheco Gandra)

Liliane Nascimento Rocha mira sua lente para a imagem (figura 10) e o trabalhador, naquele mesmo instante, também simula estar registrando a imagem da fotógrafa fazendo do olho mecânico da câmera o ponto convergente entre os dois observadores e invertendo o jogo da captura da imagem revelando as diferentes tramas do ato fotográfico. 


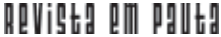

\} MOSTRA DE IMAGEM E QUESTÃO SOCIAL - DORADO, E.

DOI: $10.12957 /$ rep.2015.21074

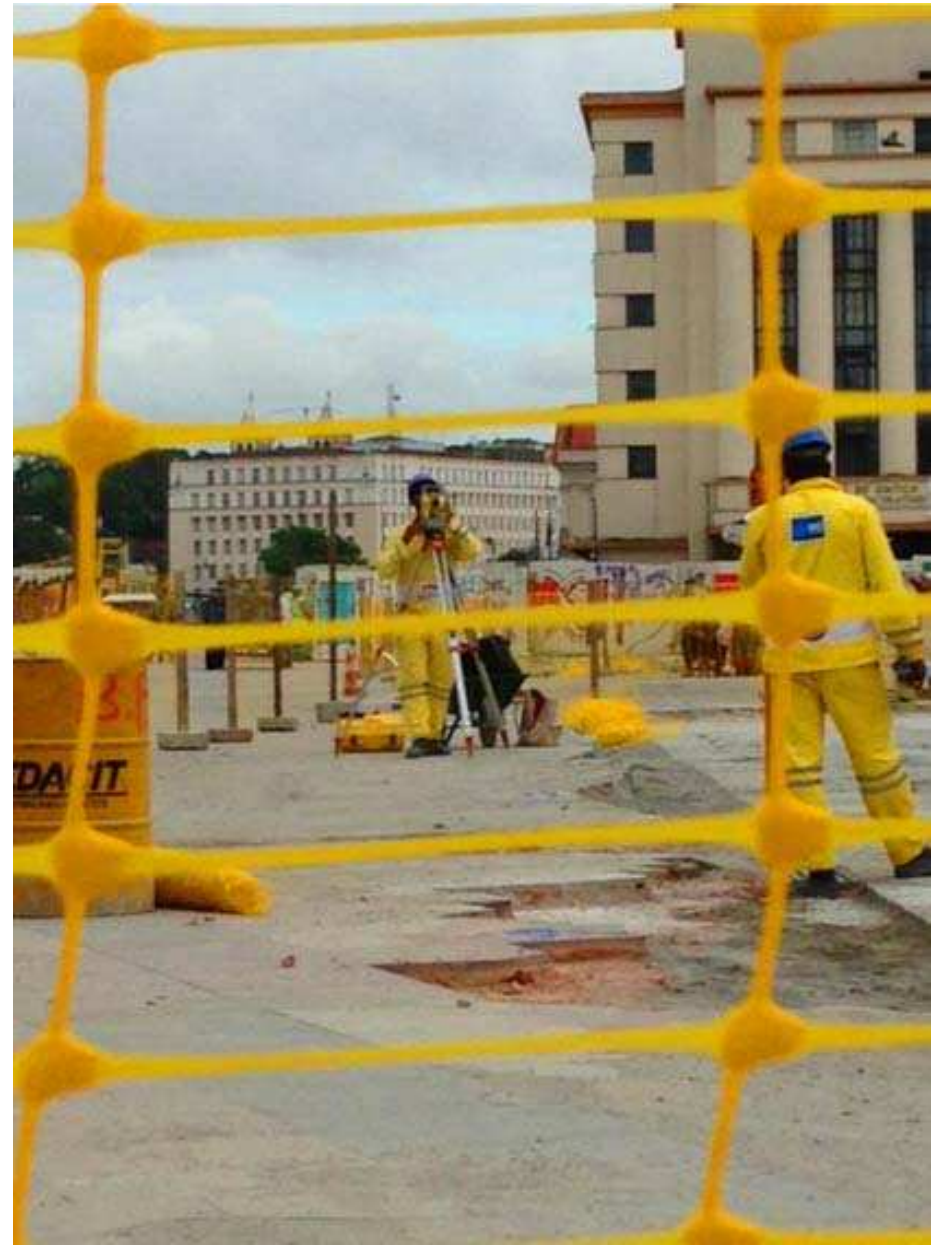

Figura 10 (Foto de Liliane Nascimento Rocha)

O olhar é uma experiência que vai muito além das demarcações rígidas de territórios e fronteiras e as imagens permitem compreender os sentidos e significados de processos sociais, em especial aqui aqueles de resistência e luta social que abrem ao leitor/observador a possibilidade de estabelecer o contraponto radical enquanto ser social e político.

Para o Laboratório de Imagem (Li) é uma oportunidade ímpar a utilização deste espaço para dar visibilidade, na área do Serviço Social e afins, de algumas reflexões e experimentações do trabalho de parcela de seus participantes que, em virtude das características particulares deste veículo, não engloba a totalidade e riqueza de suas produções e experiências. 


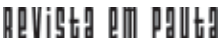

\} MOSTRA DE IMAGEM E QUESTÃO SOCIAL - DORADO, E. \}

DOI: 10.12957/rep.2015.21074

\section{Referências}

DOURADO, E. O. Mídia e trabalho docente: o quadro e o fora do quadro Revista Retratos da Escola, v.6, n.11, p. 479-488, jul. / dez. 2012.

GUERRA, R. Trabalhar com o oculto e com o que já esqueceu. Revista Cinemais, n.21, jan./fev. 2000.7-48.

MOLINA, A.M. El atrevimiento de mirar. Barcelona, Galaxia Gutemberg, 2013.

SAMAIN, E. O fotográfico. São Paulo: Hucitec,1998.

DOI: 10.12957/rep.2015.21074

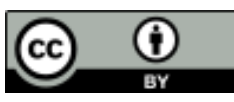

A Revista Em Pauta: Teoria Social e Realidade Contemporânea está licenciada com uma Licença Creative Commons Atribuição 4.0 Internacional. 